\title{
ARTIGO CIENTÍFICO \\ Avaliação do bagaço de cana natural e modificado como potencial sorvente de óleo vegetal
}

\author{
Evaluation of natural and modified sugarcane bagasse as sorbent of vegetable oil \\ Viviane Vasques da Silva Guilarduci ${ }^{*}{ }^{1}$, Honória de Fátima Gorgulho ${ }^{2}$, Patrícia Benedini Martelli ${ }^{3}$, Vanessa Soares dos \\ Santos $^{4}$, William Graciliano Corrêa ${ }^{5}$
}

Resumo: O óleo e a gordura vegetal residual, utilizados para a preparação de alimentos representam um perigoso poluente para as águas de córregos e rios. Um dos métodos mais utilizados nas últimas décadas para limpeza da água oleosa é a aplicação de biossorventes, pois apresentam facilidade para remoção e recuperação do óleo. Neste sentido, o objetivo deste trabalho foi determinar a influência das modificações do bagaço de cana com anidrido acético (acetilação) e com 3aminopropiltrietoxisilano (silanização) sob a sorção de óleo vegetal. A modificação das fibras foi avaliada pelas técnicas de espectroscopia no infravermelho com transformada de Fourier (FTIR), análise termogravimétrica (TG), difração de raios X, microscopia eletrônica de varredura (MEV) e análise de área superficial e porosidade. Os resultados obtidos indicaram maior sorção de óleo vegetal para o bagaço de cana modificado com anidrido acético (BCA), $667 \mathrm{mg} . \mathrm{g}^{-1}$, seguido pelo bagaço de cana sem modificação (BCN) com sorção de $576 \mathrm{mg} \cdot \mathrm{g}^{-1}$. O bagaço de cana modificado com 3-aminopropiltrietoxisilano (BCS) apresentou menor sorção, $425 \mathrm{mg} \cdot \mathrm{g}^{-1}$, o que foi atribuído à sua maior hidrofilicidade.

Palavras-chave: fibra natural; biossorção; funcionalização.

\begin{abstract}
The oil and the residual vegetable fat, used for the preparation of foods represent a dangerous pollutant for the waters of streams and rivers. One of the most used methods in the last decades for cleaning the oily water is the application of biosorbents, since they are easy to remove and recover the oil. In this sense, the purpose of this work was to determine the influence of the modifications of sugarcane bagasse with acetic anhydride (acetylation) and with 3-aminopropyltriethoxysilane (silanization) under sorption of vegetable oil. The BCN and the grafted products were further characterized by FTIR spectroscopy, thermal gravimetric analysis, $\mathrm{X}$-ray diffraction, scanning electron microscopy and analysis of surface area and porosity. The results showed higher sorption of vegetable oil for the acetic anhydride-modified sugarcane bagasse (BCA), 667 mg.g-1, followed by sugarcane bagasse without modification (BCN) with sorption of $576 \mathrm{mg} . \mathrm{g}-1$. The cane bagasse modified with 3-aminopropyltriethoxysilane (BCS) presented lower sorption, $425 \mathrm{mg} . \mathrm{g}-1$, which was attributed to its greater hydrophilicity.
\end{abstract}

Key words: natural fiber; biosorption; functionalization.

\footnotetext{
*Autor para correspondência

Recebido para publicação em 31/03/2016; aprovado em 05/09/2016

${ }^{1}$ Doutoranda em Química e Física de Materiais pela Universidade Federal de São João del-Rei (UFSJ), São João del-Rei - M.G.; (32) 98809-0045, viviane.guilarduci@ifsudestemg.edu.br.

${ }^{2}$ Doutora em Ciências (Físico-Química), Professora adjunto-IV da Universidade Federal de São João del-Rei (UFSJ), gorgulho@ufsj.edu.br.

${ }^{3}$ Doutora em Química (Química Analítica), Professora Associada I da Universidade Federal de São João del-Rei (UFSJ), martelli@ufsj.edu.br.

${ }^{4}$ Graduanda em Química/Bacharelado - Universidade Federal de São João del-Rei (UFSJ), vaa.soares@ hotmail.com.

${ }^{5}$ Graduando em Química/Bacharelado - Universidade Federal de São João del-Rei (UFSJ), will_1997cr@bol.com.br.
} 


\section{INTRODUÇÃO}

O óleo e a gordura vegetal residual, utilizados para a preparação de alimentos representam um perigoso poluente para as águas de córregos e rios (WILDNER; HILLIG, 2012). Apesar de existirem processos para a reciclagem destes resíduos, a maior parte dos resíduos de óleos vegetais gerados nas residências são destinados ao solo ou mesmo ao esgoto doméstico. Como resultado os efluentes de esgotos urbanos são caracterizados por uma elevada carga orgânica, que, em sua degradação aeróbica, demanda alta concentração de oxigênio, afetando a respiração dos peixes e outras formas de vida (PEREIRA, 2004).

As caixas de gordura são dispositivos usados para retenção de óleos e gorduras proveniente de pias de cozinha. Sua instalação é exigida por muitos municípios para liberação de ligações de esgoto, entretanto não existe um sistema de coleta e pré-tratamento dos resíduos retirados das caixas de gordura. Dessa forma, em geral, estes resíduos são lançados no sistema público de coleta sem tratamento, ou dispersos no solo comprometendo assim os lençóis freáticos (OLIVEIRA et al., 2014)

Nas estações de tratamento de água, a presença de óleos e gorduras provocam obstrução em redes coletoras de esgotos e inibição dos processos biológicos de tratamento. Isto faz com que as empresas implantem o pré-tratamento destes efluentes (WILDNER; HILLIG, 2012). Para que sejam atendidos os padrões ambientais de descarte e/ou as características necessárias para o reuso da água, o tratamento de uma água oleosa pode se tornar uma operação complexa e dependente de processos altamente onerosos. Processos químicos, mecânicos e biológicos podem ser usados para remover, recuperar ou degradar o óleo de águas contaminadas.

Um dos métodos mais utilizados nas últimas décadas para limpeza da água oleosa é a aplicação de materiais sorventes, pois apresentam facilidade para remoção e recuperação do óleo (TEAS et al., 2010) Vários são os tipos de materiais que podem ser utilizados para a sorção. Estes podem ser classificados em três classes principais: produtos minerais inorgânicos, orgânicos sintéticos, produtos orgânicos naturais. Produtos minerais incluem grafite, perlita, vermiculitas, argila absorvente e diatomite (CHOI; CLOUD, 1992). Produtos sintéticos incluem polipropileno e espuma de poliuretano. Estes materiais apresentam em geral um alto poder de sorção de óleos e graxas, porém apresentam a desvantagem de se degradarem muito lentamente no meio ambiente (TEAS et al., 2010). Produtos orgânicos naturais, também conhecidos como biossorventes, são aqueles provenientes de materiais da natureza, sendo constituídos principalmente de carbono, são eles: serragem, algodão, turfa, bagaço de cana, palha e sabugo de milho, entre outros (ANNUNCIADO et al., 2005).

Os biossorventes apresentam-se como uma boa alternativa para adsorção de óleos, pois apresentam boa flutuabilidade, baixo custo, abundância na natureza, não necessitam de regeneração e apresentam a vantagem de sua natureza celulósica auxiliar na degradação do óleo em sistemas aquosos (FERREIRA, 2009).

O bagaço de cana (BC) é um resíduo agrícola gerado em abundância pela agroindústria brasileira, estima-se que a produção total de cana de açúcar na safra 2014/15 foi de 642,1 milhões de toneladas (CONAB, 2014). A quantidade de
BC obtida nas usinas varia de acordo com o teor de fibra da celulose e com o nível tecnológico empregado na moagem. Este valor é em média de $29 \%$ do volume total da cana processada, o que representou a geração de cerca de 200 milhões de toneladas de BC para a safra 2014/2015 (CONAB, 2014).

O BC é principalmente constituído por celulose (30$50 \%$ ), cuja unidade repetitiva é composta por duas moléculas de glicose esterificadas por ligações $\beta$-1,4-glicosídicas (TELI; VALIA, 2013). Esta unidade repetitiva, conhecida como celobiose, contém seis grupos hidroxila que estabelecem interações do tipo ligações de hidrogênio intra e inter molecular. A funcionalização da celulose envolve principalmente os grupos hidroxilas, os quais podem reagir com uma variedade de ligantes (MOHAMMEDA et al., 2013). Pode-se, por exemplo, modificar a natureza hidrofílica da celulose. A acetilação é o principal meio para introduzir grupos apolares à superfície da fibra, favorecendo sua interação com polímeros, óleos e graxas. Por outro lado, a introdução de grupos silanos organofuncionalisados (silanos ou organossilanos) na superfície da fibra pode aumentar a hidrofilicidade. Estes são compostos de silício representados pela fórmula $\mathrm{X}_{3}-\mathrm{Si}-\mathrm{R}-\mathrm{Y}$, onde $\mathrm{Y}$ representa o grupo funcional orgânico, escolhido em função de sua reatividade, ligado ao silício através de uma ponte alquila. $\mathrm{X}$ representa grupos hidrolisáveis como alcóxidos, alcilóxidos e outros, intermediários na formação de grupos silanóis, os quais reagem com as hidroxilas da superfície das fibras (ABDELMOULEH et al., 2002). Assim, é possível inserir grupos de interesse na superfície de diversos biossorventes, através de ligações covalentes.

Neste sentido, objetivou-se determinar a influência das modificações do bagaço de cana (BC) com anidrido acético (acetilação) e com 3-aminopropiltrietoxisilano (silanização) sob a sorção de óleo vegetal.

\section{MATERIAL E MÉTODOS}

\section{Preparação das fibras}

$\mathrm{O} \mathrm{BC}$ foi fornecido pelo alambique " $C A C H A C ̧ A$ COQUEIRO”, do município de Nazareno, MG- Brasil. O BC foi previamente lavado com água destilada a $80^{\circ} \mathrm{C}$ por diversas vezes, e posteriormente seco em estufa com circulação de ar (Quimis, Q314M) a $60^{\circ} \mathrm{C}$ até completa secagem (aproximadamente 24h). O BC foi então triturado em um micro moinho tipo Willye (Tecnal, TE648), coletando-se a porção das fibras que passou pela peneira de 30 mesh (partículas menores que 0,595 mm), desprezando-se a primeira e a última parcela da moagem. Estas amostras foram denominadas bagaço de cana natural (BCN).

\section{Funcionalização do BC Acetilação}

As fibras de $\mathrm{BC}$ foram embebidas em solução aquosa de $\mathrm{NaOH} 10 \%$ a $0{ }^{\circ} \mathrm{C}$ por $1 \mathrm{~h}: 30 \mathrm{~min}$. Em seguida as fibras foram lavadas com água destilada, na temperatura ambiente, até o $\mathrm{pH}$ da água de lavagem estar próximo de 7. As fibras foram então secas em estufa com circulação de ar por $24 \mathrm{~h}$ a $60^{\circ} \mathrm{C}$.

A acetilação foi realizada utilizando anidrido acético para a substituição dos grupos hidroxilas $(-\mathrm{OH})$ presentes nas paredes da celulose pelo grupo acetila, dando a estas um caráter apolar característico deste grupo; ácido acético, cuja maior contribuição está diretamente ligada ao intumescimento 
das fibras (aumento de volume) e ácido sulfúrico como catalizador da reação. Para isso, $100 \mathrm{~g}$ de BC foi misturado com $285 \mathrm{~mL}$ de ácido acético, $400 \mathrm{~mL}$ de anidrido acético e 1 $\mathrm{mL}$ de ácido sulfúrico e deixado em banho maria incubadora (Nova Ética, NE4967) por $24 \mathrm{~h}$ a uma temperatura de $60^{\circ} \mathrm{C}$. Decorrido o tempo de reação, as fibras foram repetidamente lavadas até que apresentasse $\mathrm{pH}$ entre 5-6 na solução de lavagem final e secas em estufa com circulação de ar (Quimis, Q314M) a $60^{\circ} \mathrm{C}$ durante $24 \mathrm{~h}$. Estas amostras foram denominadas de BCA.

\section{Modificação com grupo silano}

Neste processo foi utilizado como agente silano modificador o 3-aminopropiltrietoxisilano (APS) mostrado na Figura 1.

Figura 1. 3-Aminopropiltrietoxisilano (APS)

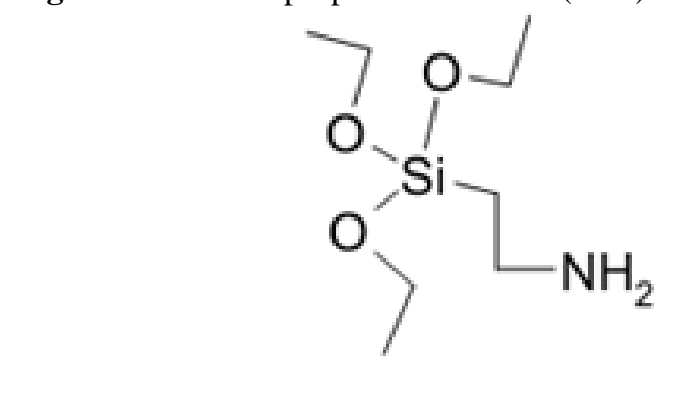

Fonte: Mesquita (2006)

A reação do BC com APS foi realizada por via seca, em que $40 \mathrm{~g}$ do silano é previamente misturado em $400 \mathrm{~mL}$ de acetona e posteriormente com $100 \mathrm{~g}$ de fibra. A mistura é deixada em agitação em moinho de rolete (Tecnal, TE500/1) por $24 \mathrm{~h}$. Após o tempo de reação, as fibras são secas em estufa com circulação de ar (Quimis, Q314M) a $60^{\circ} \mathrm{C}$ por 24h. A mistura final é limpa em extrator soxhlet com acetona. O APS possui grupos polares que favorecem a afinidade da superfície com solventes aquosos, favorecendo a sorção de cátions. As fibras modificadas foram denominadas BCS.

\section{Caracterização das fibras}

A funcionalização foi caracterizada por espectroscopia no infravermelho com transformada de Fourier (FTIR), análise termogravimétrica (TG), difração de raios-x, microscopia eletrônica de varredura $(\mathrm{MeV})$ e análise de área superficial e porosidade.

\section{Ensaios de Sorção}

A metodologia utilizada para realização dos testes de sorção de óleos pelas fibras foi adaptada da proposta de Annunciado et al. (2005). Os ensaios de sorção foram realizados com óleo vegetal ABC comercial. Para cada 10,0g de fibra foram usados $11,4 \mathrm{~g}$ de óleo por litro de água, os quais foram deixados em contato por $24 \mathrm{~h}$ em repouso (método estático). No final as fibras foram filtradas a vácuo e deixadas por $24 \mathrm{~h}$ para secagem em temperatura ambiente. As fibras foram pesadas e a quantidade de óleo sorvido foi dado em $\mathrm{mg}$ de óleo/g de fibra a partir da equação 1 :

$$
\mathrm{S}=\frac{\left(\mathrm{S}_{\mathrm{t}}-\mathrm{S}_{0}\right)}{\mathrm{S}_{0}}
$$

Onde $S_{\mathrm{t}}$ é a massa total corrigida para as amostras após sorção e $S_{o}$ a massa inicial das fibras. Foi feito um branco para cada medida de onde se obtiveram as correções para a sorção do papel de filtro.

\section{RESULTADOS E DISCUSSÃO}

O resultado das análises de FTIR das amostras estão mostrados na Figura 2. A fibra BCA apresenta no espectro de FTIR bandas características de vibração do grupo acetila, em cerca de $1740-1750 \mathrm{~cm}^{-1}$ (estiramento $\mathrm{C}=\mathrm{O}$ da carbonila), $1368 \mathrm{~cm}^{-1}$ (deformação $\mathrm{C}-\mathrm{H}-\mathrm{O}(\mathrm{C}=\mathrm{O})-\mathrm{CH}_{3}$ ) e $1230-1240 \mathrm{~cm}^{-1}$ (estiramento de $\mathrm{CO}$ do grupo acetila), as quais estão ausentes no espectro do BCN, estes resultados estão de acordo com Mohammeda et al., (2013). De acordo com Aguiar et al., (2012) e Hokkanen et al., (2014) observa-se para o BCS banda próxima a $1095 \mathrm{~cm}^{-1}$, relacionada ao estiramento assimétrico da ligação Si-O-Si e as bandas entre 1000 e 800 $\mathrm{cm}^{-1}$ relacionadas com as ligações $\mathrm{Si}-\mathrm{O}-$ Celulose e $\mathrm{Si}-\mathrm{O}-\mathrm{C}$.

Figura 2. Espectroscopia no Infravermelho do BCN, BCA e BCS.

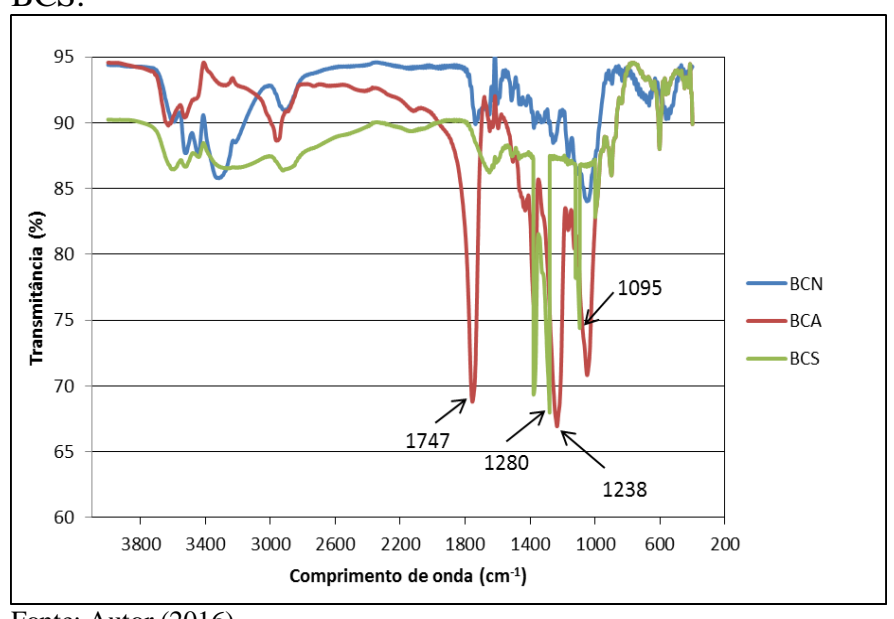

Fonte: Autor (2016)

Os resultados da TG estão mostrados na Figura 3. Podese verificar que as amostras após funcionalização apresentam maior estabilidade térmica em relação ao BCN. Este resultado comprova que ocorreu mudança na composição das fibras após funcionalização, o que é concordante com os dados de FTIR. Outros autores também observaram através da TG o aumento da temperatura de degradação das fibras funcionalizadas por acetilação ou silanização (ABDELMOULEH et al., 2002; TELI; VALIA, 2013). Os perfis dos TGs mostram que a decomposição térmica destas amostras ocorre em três etapas: primeira, uma pequena perda de massa até aproximadamente $105^{\circ}$, referente a evaporação da água, a segunda entre $250^{\circ}$ e $350^{\circ} \mathrm{C}$ referente as quebras das moléculas de celulose e a terceira entre $450^{\circ} \mathrm{C}$ e $550^{\circ} \mathrm{C}$ referente a quebra de ligações da lignina. Entre $105^{\circ} \mathrm{C}$ e $250^{\circ} \mathrm{C}$ existe um platô de temperatura referente ao aquecimento de celulose sem quebra de ligação (LEI, 2013). 
Figura 3. Análise termogravimétrica das fibras BCN, BCA e BCS.

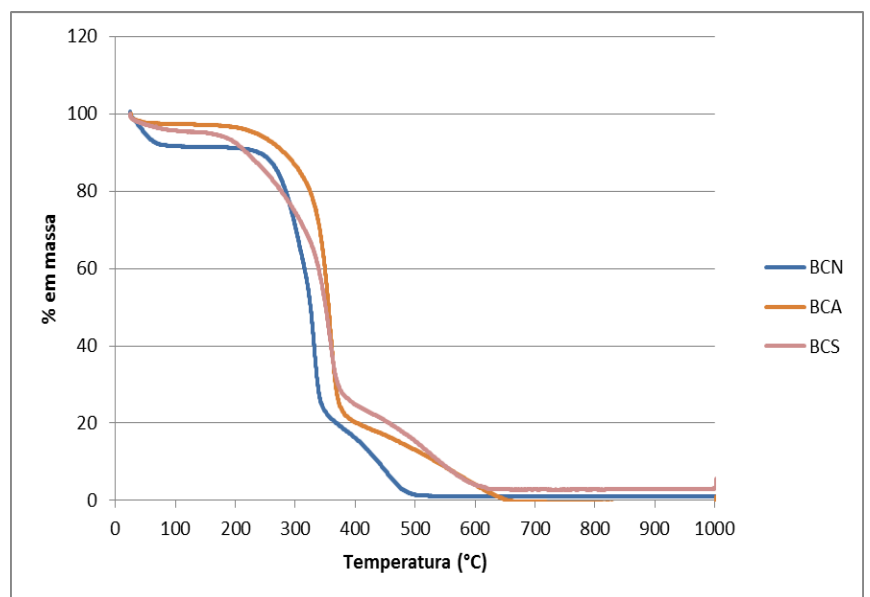

Fonte: Autor (2016)

A cristalinidade das amostras de BCN, BCA e BCS foi avaliada pela técnica de difração de raios $X$. Pelos difratogramas apresentados na Figura 4, observamos que houve diminuição dos picos de difração do BCS e BCA em relação ao BCN. De acordo com Olaru et al. (2011) o pico que aparece entre $2 \theta=5^{\circ}$ e $2 \theta=10^{\circ}$ para o BCA é característico do acetato de celulose que foi introduzido com a acetilação.

Figura 4 - Difratogramas de raios-x das fibras BCN, BCA e BCS.

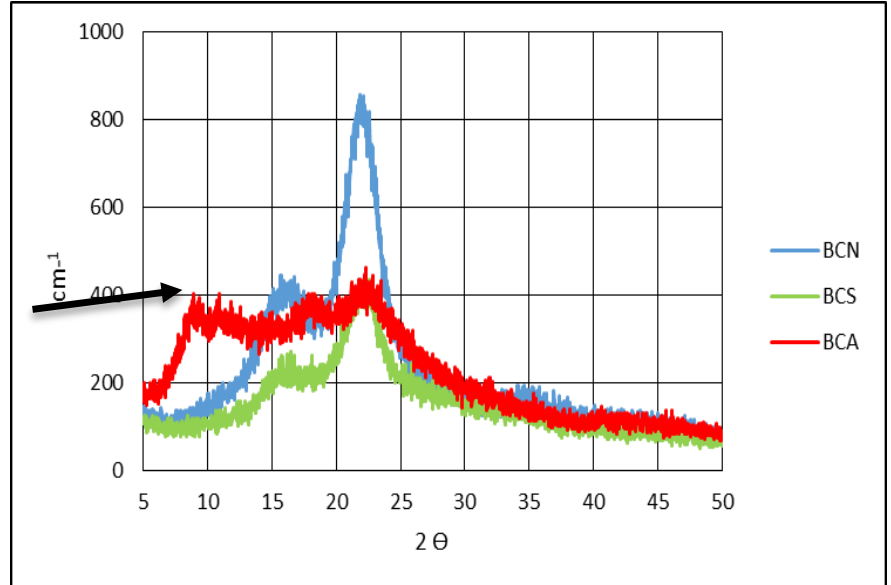

Fonte: Autor (2016)

A partir dos dados obtidos pelos difratogramas de raios$\mathrm{x}$, calculou-se o índice de cristalinidade (Ic) pela fórmula desenvolvida por Segal et al. (1959). De acordo com os dados apresentados na Tabela 1, a funcionalização alterou a estrutura das fibras diminuindo seu índice de cristalinidade (Ic), ou seja, ocorreu decréscimo da cristalinidade para as fibras funcionalizadas. Esse resultado é esperado, pois a cristalinidade está relacionada com as interações intermoleculares das fibras, as quais são favorecidas pelos grupos hidroxila. Pode-se verificar pelas Figuras 5A e 5B, que as reações de funcionalização utilizam estes grupos hidroxilas para introdução dos grupos funcionais, o que interfere na cristalinidade das fibras.
Tabela 1 - Índice de cristalinidade obtidos através do difratograma de raios-x para as fibras BCN, BCA e BCS

\begin{tabular}{cc}
\hline Tipo de Fibra & Ic $(\%)$ \\
\hline BCN & 64,95 \\
BCS & 58,26 \\
BCA & 32,03 \\
\hline
\end{tabular}

Figura 5. (A) Possível reação entre anidrido acético e bagaço de cana; (B) possível reação entre o APS e o bagaço de cana.<smiles>CCC(O)CC(O)CC(C)CC(O)CC(C)CC(O)CC(C)O</smiles>

Fonte: Autor (2016)

Os resultados do estudo da sorção de óleo vegetal em meio aquoso pelas fibras de $\mathrm{BCN}$, BCA e BCS estão mostrados nas Figuras 6 e 7. Neste processo a afinidade do sorvente pela água pode reduzir o contato com o óleo e sua captura nos poros do material. A Figura 6 apresenta a sorção de água para as amostras estudas (BCN, BCA e BCS). Em relação a fibra natural, a funcionalização com organossilano aumenta a afinidade pela água. Este resultado se deve aos grupos básicos $\left(-\mathrm{NH}_{2}\right)$ do APS que interagem com a água de acordo com a equação mostrada na Figura 8. No caso da fibra acetilada o resultado é o oposto, ou seja, diminui a sorção de água. Este comportamento da fibra pode ser atribuído à substituição dos grupos hidroxila por grupos acetila, no processo de funcionalização, o que favorece o caráter hidrofóbico da fibra. Este efeito é positivo para sorção de moléculas apolares como os óleos, como podemos observar nos resultados mostrados na Figura 7, em conformidade com Alfaya e Alfaya (2013).

Figura 6. Sorção de água pelas fibras BCN, BCA e BCS.

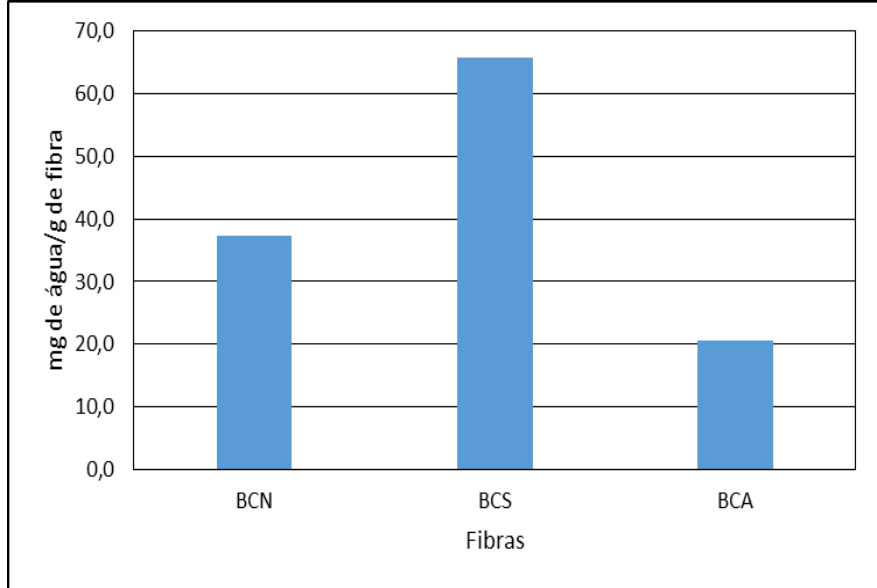

Fonte: Autor (2016)

A Figura 7 mostra que a sorção do óleo vegetal é favorecida pela introdução de grupos apolares na fibra, o que aumenta seu caráter hidrofóbico. Este é o caso da fibra 
acetilada, em que a funcionalização pode introduzir grupos apolares e também modificar as propriedades texturais, conforme apresentado na Tabela 2.

Figura 7. Sorção de óleo pelas fibras BCN, BCA e BCS

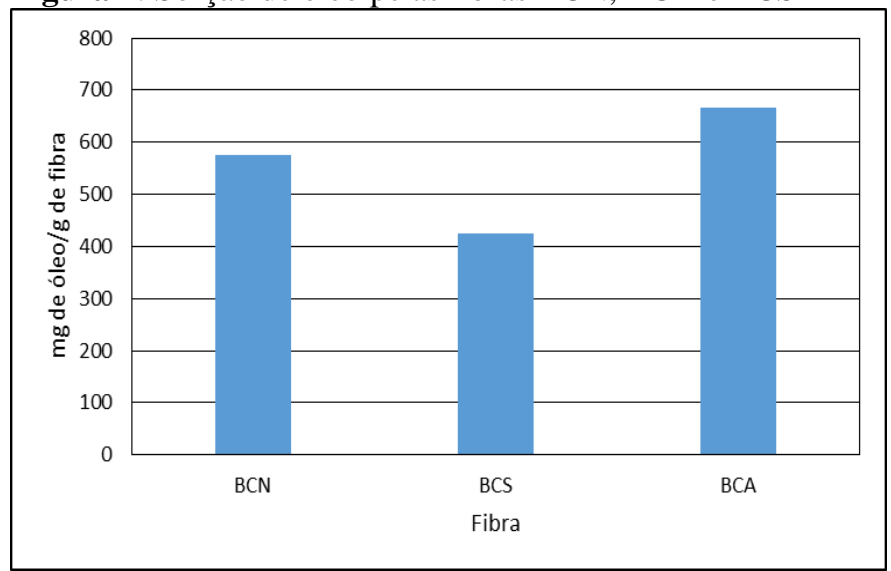

Fonte: Autor (2016)

Figura 8. Representação do equilíbrio em meio aquoso envolvendo o grupo $-\mathrm{NH}_{2}$ do APS na fibra BCS.

$$
-\mathrm{NH}_{2}+\mathrm{H}_{2} \mathrm{O} \rightleftharpoons-\mathrm{NH}_{3}^{+}+\mathrm{OH}^{-}
$$

Fonte: Autor (2016)

Tabela 2 - Resultados das análises texturais (BJH) do BCN, BCA e BCS.

\begin{tabular}{ccc}
\hline Fibra & $\begin{array}{c}\text { Área superficial } \\
\mathrm{m}^{2} / \mathrm{g}\end{array}$ & $\begin{array}{c}\text { Volume total de poros } \\
\mathrm{cm}^{3} / \mathrm{g}\end{array}$ \\
\hline $\mathrm{BCN}$ & 9,644 & 0,013 \\
$\mathrm{BCA}$ & 10,724 & 0,015 \\
$\mathrm{BCS}$ & 9,343 & 0,013 \\
\hline
\end{tabular}

A Figura 9 mostra as imagens do MEV que apresenta o aspecto superficial da fibra BCN (Figura 9A), BCA (Figura 9B) e BCS (Figura 9C). Percebe-se que na fibra acetilada (Figura 9B) os blocos de fibras estão mais alongados, com aspecto mais poroso, justificando o leve aumento da área superficial observado na Tabela 2 . O processo de acetilação elimina as substâncias que influenciam diretamente na hidrofilicidade como a pectina, a lignina e a cera amorfa, presente nas cutículas das fibras (LOPES et al, 2010).

Figura 9 - Microscopia eletrônica de varredura do BCN (A), BCA (B) e BCS (C).

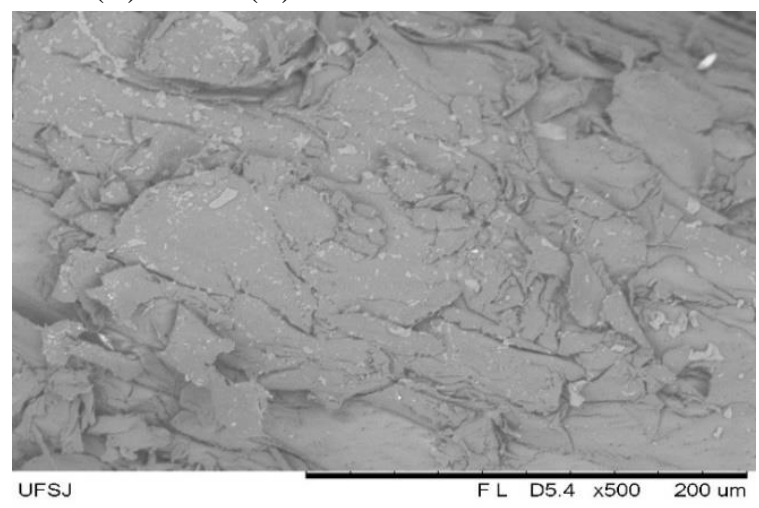

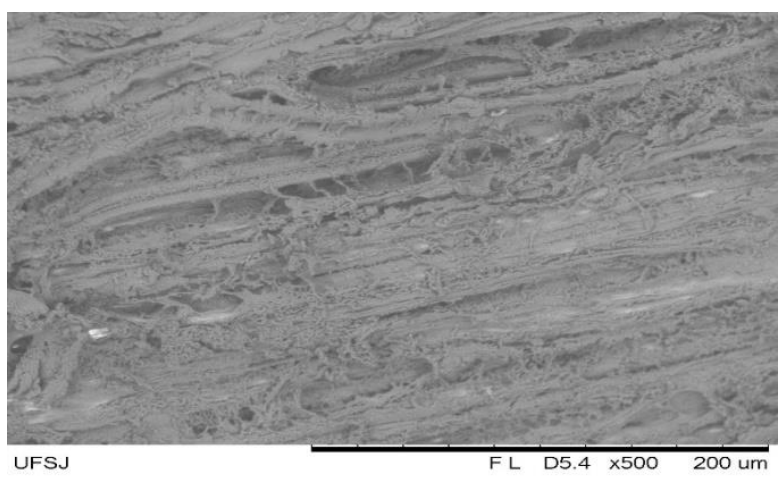

B.

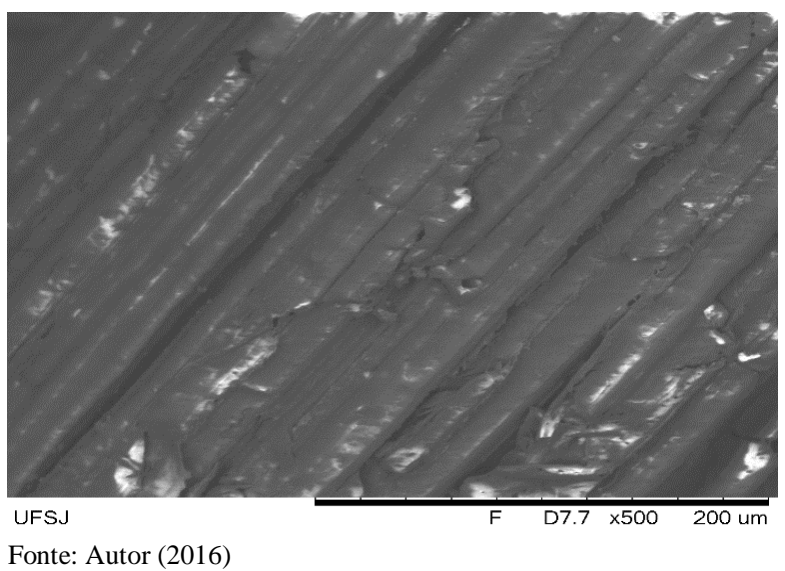

C.

\section{CONCLUSÕES}

A introdução de grupos acetato no BC tornou a fibra menos cristalina, aumentou sua área superficial e volume de poros, favorecendo a sorção de óleo.

As duas funcionalizações realizadas com o $\quad$ BC modificaram suas propriedades térmicas.

A fibra de $\mathrm{BC}$ na forma natural e modificada por processos de acetilação com anidrido acético e silanização com APS foram avaliadas como potencial sorvente de óleo vegetal e concluiu-se que a modificação do BC com APS favorece o caráter hidrofílico da fibra, aumentando a sua capacidade de sorção de água e diminuindo a capacidade de sorção de óleo.

A fibra BCA apresentou maior sorção de óleo vegetal, $666,8 \mathrm{mg} \cdot \mathrm{g}^{-1}$, enquanto a fibra BCN apresentou 576,2 mg.g ${ }^{-1}$. O BCS apresentou menor capacidade de sorção de óleo, 424,9 $\mathrm{mg} \cdot \mathrm{g}^{-1}$. Este comportamento foi atribuído à sua maior hidrofilicidade.

\section{AGRADECIMENTOS}

Á Fundação de Amparo à Pesquisa do Estado de Minas Gerais (FAPEMIG) e ao Instituto Federal do Sudeste de Minas Gerais (IF Sudeste MG) - Campus São João delRei.

\section{REFERÊNCIAS}

ABDELMOULEH, M.; BOUFI, S.; SALAH, A. B.; BELGACEM, M. N., GANDINI, A. Interaction of silane coupling agents with cellulose. Langmuir, v.18, n.8, p.32033208, 2002. 
AGUiAR, K. R., BAtAlHA, G. P., PEIXOTO, M., RAMOS, A., PEZZIN, S. H. Produção de membranas híbridas zirconizadas de SPEEK/Copolissilsesquioxano para aplicação em células a combustível do tipo PEM. Polímeros, v.22, p.453-459,2012.

ALFAYA, R. V. S ; ALFAYA, A. A. S. Chemically modified natural cotton fiber: a low-cost biosorbent for the removal of the $\mathrm{Cu}(\mathrm{II}), \mathrm{Zn}(\mathrm{II}), \mathrm{Cd}(\mathrm{II})$, and $\mathrm{Pb}$ (II) from natural water. Desalination and Water Treatment, v. 54, p. 1-11, 2013.

ANNUNCIADO, T. R; SYDENSTRICKER, T. H. D.; AMICO S. C. Experimental investigation of various vegetable fibers as sorbent materials for oil spills. Marine Pol. Bul. v.50, p.1340-1346, 2005.

CHOI, H. M.; CLOUD, R. M. "Natural sorbents in oil spill cleanup". Environmental Science and technology, v. 26, p.772-776, 1992.

CONAB, COMPANHIA NACIONAL DE ABASTECIMENTO. Acompanhamento da safra brasileira de cana-de-açúcar/ relatório 6 - matéria prima cana de açúcar, v. 1 - Safra 2014/15, n. 3 - Terceiro Levantamento, Brasília, dez. 2014.

FERREIRA, T. Sorção de petróleo em fibras vegetais. Natal: UFRN, 2009. 65p.

HOKKANEN, S.; REPO, E.; SUOPAJARVI, T.; LIIMATAINEN, H.; NIINIMAA, J.; SILLANPAA, M. Adsorption of $\mathrm{Ni}(\mathrm{II}), \mathrm{Cu}(\mathrm{II})$ and $\mathrm{Cd}(\mathrm{II})$ from aqueous solutions by amino modified nanostructured microfibrillated cellulose. Cellulose, v.21, p.1471-1478, 2014.

LEI, W. Literature Review of Cellulose Acetylation. Puu0.4100 Advanced Biomaterial Chemistry and Technology course report. AALTO UNIVERSITY, Finlândia, 2013.

LOPES F. F. M.; ARAÚJO, G. T.; NASCIMENTO J. W. B.; GADELHA T. S.; SILVA V. R. Estudo dos efeitos da acetilação em fibras de sisal. Revista Brasileira de Engenharia Agrícola e Ambiental v.14, n7, p.783-788, 2010.

MESQUITA, A. R. A casca de arroz funcionalizada com Organossilanos para Aplicação como Adsorvente de Metais Pesados. Dissertação de Mestrado: UFSJ, 2006.
MOHAMMEDA, R. R.; IBRAHIMA, A. R. I.; TAHAB, H. A.; MCKAY, G. Waste lubricating oil treatment by extraction and adsorption. Chemical Eng. J., v.220, p. 343-351, 2013.

OLARU, N., OLARU, L., VASILE, C., ANDER, P. Surface modified cellulose obtained by acetylation without solvents of bleached and unbleached kraft pulps. Polimery, v.56, p.834840, 2011.

OLIVEIRA, J. P.; ANTUNESA, P. W. P.; PINOTTIB, L. M.; CASSINIA, S. T. A. Caracterização físico-química de resíduos oleosos do saneamento e dos óleos e graxas extraídos visando a conversão em biocombustíveis. Quim. Nova, V.37, n $^{\circ}$, p.597-602, 2014.

PEREIRA, R. S. Identificação e caracterização das fontes de poluição em sistemas hídricos. Revista eletrônica de recursos hídricos. IPH - UFRGS. V.1, n¹, p.20-36, 2004.

SEGAL L., CREELY J. J., MARTIN A. E. JR., CONRAD C. M. An empirical method for estimating the degree of crystallinity of native cellulose using the X-ray diffractometer. Textile Research Journal, v.29, p.786-794, 1959.

TEAS, C.; KALLIGEROS, S.; ZANIKOS, F.; STOUMAS, S.; LOIS, E.; ANASTOPOULOS, G. Investigation of the effectiveness of absorbent materials in oil spills clean up. Desalination, v.140, issue 3, p.259-264, 2010.

TELI, M. D.; VALIA, S. P. Acetylation of banana fiber to improve oil absorbency. Carb. Poly., v.92, p.328-333, 2013.

WILDNER, L. B. A.; HILLIG C. Reciclagem de óleo comestível e fabricação de sabão como instrumentos de educação ambiental. Revista Eletrônica em Gestão, Educação e Tecnologia Ambiental REGET/UFSM, v.5, n5, p.813 824, 2012. 